1 Notice

2 This manuscript is submitted to EarthArXiv as a pre-print and has not yet been peer-reviewed. Please 3 note that following peer-review, subsequent versions of this paper may have slightly different 4 content. If accepted for publication, the final version of this pre-print will also be made available, 5 subject to the period of embargo imposed by the Journal. Please feel free to contact the 6 corresponding author directly. We welcome constructive feedback.

Title: No demonstrated link between sea-level and eruption history at Santorini.

Authors: RJ Walker ${ }^{*}$, SPA Gill², C Greenfield ${ }^{1}$, KJW McCaffrey $^{3}$, TStephens $^{4}$

Affiliations: ${ }^{1}$ School of Geography, Geology, and the Environment, University of Leicester, University Road, Leicester, LE1 7RH, UK. ${ }^{2}$ Department of Engineering, University of Leicester, University Road, Leicester, LE1 7RH, UK. ${ }^{3}$ Department of Earth Sciences, Durham University, Science Labs, Durham, DH1 3LE, UK. ${ }^{4}$ School of Geosciences, King's College, University of Aberdeen, Aberdeen, AB24 3UE, 17 UK

Corresponding Author: rich.walker@le.ac.uk 


\title{
No demonstrated link between sea-level and eruption history at Santorini
}

\author{
RJ Walker ${ }^{1 *}$, SPA Gill2, C Greenfield ${ }^{1}$, KJW McCaffrey ${ }^{3}$, T Stephens ${ }^{4}$ \\ 1. School of Geography, Geology, and the Environment, University of Leicester, University Road, Leicester, LE1 7RH, UK. \\ 2. Department of Engineering, University of Leicester, University Road, Leicester, LE1 7RH, UK. \\ 3. Department of Earth Sciences, Durham University, Science Labs, Durham, DH1 3LE, UK \\ 4. School of Geosciences, King's College, University of Aberdeen, Aberdeen, AB24 3UE, UK \\ *Corresponding author: rich.walker@le.ac.uk
}

Previous studies have suggested a link between rates of sea-level variation and eruptions globally [McGuire et al., 1997], with Satow and coauthors [2021] presenting the first detailed comparison between sea-level change and eruptive history for a single island-volcano. They use robust, highresolution ages for volcanic deposits at Santorini, combined with a 2D numerical model to correlate sea-level reduction with volcanism. Lowering sea level reduces overburden pressure and is predicted to increase tensile stress in the magma chamber roof, leading to diking and eventually eruption. Having independently reproduced their results, we disagree with the numerical model for three main reasons: (1) predictions of stress distribution and magnitudes caused by sea level change are solely dependent on the size and boundary conditions of the 2D model; (2) minor changes to the model dimensions, dimensionality (2D to 3D), and/or addition of a mantle analogue, removes correlation between sea level and eruptions; and (3) crustal loading conditions at the volcano absent from the model are more significant than sea level change.

\section{The result relates to the exact geometry and dimensionality of the model}

Although not explicitly stated in the paper, the Satow et al. [2021] 2D model (Fig. 1a) is an elastic bending beam configuration (Fig. 1b), with the vertical ends fixed in position, and top and bottom boundaries free to move up or down because there is no mantle. Modelled stresses for this configuration are proportional to central displacement of the beam, $\delta \propto w^{4} h^{-3}$; it is strongly dependent on the width, $w$, and/or thickness, $h$ (Fig. 1C,d). Stresses at the maximum displacement will be large even without a magma chamber (Fig. 1e). Stress at the chamber depends on its lateral and vertical position within the beam, with stress becoming compressive if it is located towards one end, or below $\sim 10 \mathrm{~km}$ if centralised (Fig. 1b), which is important to the multiple magma storage depths at Santorini [Druitt et al., 2019].

In the published model, a sea level reduction of about $-40 \mathrm{~m}$ (more precisely $-44 \mathrm{~m}$ from our reproduction; - $0.4 \mathrm{MPa}$ lithostatic pressure change) results in elevated tensile stress at the magma chamber (3.5 $\mathrm{MPa}$ ) causing diking. At -70 to $-80 \mathrm{~m}$, the tensile stress region above the chamber reaches the surface, causing eruption [Satow et al. 2021]. These are changes in stress for the specific width $(100 \mathrm{~km})$ and thickness $(20 \mathrm{~km})$ of elastic crust in the published model, which is described as being large enough to avoid edge effects at the chamber. The model size, with fixed vertical boundaries, may represent an average of the radial distances to the other islands in the Cyclades $(\sim 30 \mathrm{~km})$, and Crete ( 100 km), and an average elastic plate thickness (Gudmundsson, 2021 pers. comm., 5 August). Changing the model width by $+20 \mathrm{~km}$ or $-20 \mathrm{~km}(20 \%)$ changes the critical sea level value from $-40 \mathrm{~m}$, to $-30 \mathrm{~m}$ or $-70 \mathrm{~m}$ respectively (Fig. 1d); hence choosing width as an average of 30 and $100 \mathrm{~km}$ is not adequate. In the bending beam configuration, the Cyclades would act as small bumps on the surface of the model with little effect on whole beam bending. In reality, no part of the crust is locked into a fixed position, but the closest physical representation of this condition is perhaps the edge of the Aegean Sea and/or Sea of Crete, $>100 \mathrm{~km}$ from Santorini. Increasing the Satow et al. [2021] 2D beam model to $w=200 \mathrm{~km}$ (Fig. 1C), $-110 \mathrm{~m}$ sea level change 
results in a central displacement of 223 m; i.e., double the maximum sea level change [Grant et al., 2014].

Changing the dimensionality of the model, from 2D to 3D, also has significant impact on the results. Figure If shows an axisymmetric (3D) version of the Satow et al. [2021] model, which would be expected to be an improvement on the $2 \mathrm{D}$ model presented in the paper. Now the crust is much harder to bend, lowering the maximum tensile stress at $-44 \mathrm{~m}$ from $3.5 \mathrm{MPa}$ in the $2 \mathrm{D}$ case to 1.5 $\mathrm{MPa}$ in the 3D case, changing their diking condition from $-44 \mathrm{~m}$ to $-105 \mathrm{~m}$ (Fig. 1d). As before, this model is still very sensitive to the width and height of the simulated crust.

In reality, bending of the plate will be subdued or removed by the viscous lower crust or mantle, which is absent in the model. To simulate this, we have altered the axisymmetric model to include a viscous region coupled to the base of the elastic plate (Fig. 2). There is now no need to constrain the edges of the simulation vertically, as this constraint is supplied by the mantle; deformation is now local to the chamber, so the crust width and height are no longer important. The maximum tensile stress change at $-110 \mathrm{~m}$ is $11.3 \mathrm{MPa}$, but at the horizontal tips (Fig. 2), and now relates to the specific shape of the chamber [Kirsch, 1898]. Adding the mantle would be an improvement, but other essential physics should be included to properly explore the effects of unloading (e.g., [Sigmundsson et al., 2010])

\section{Minor changes to the model remove correlation between eruptions and sea level change}

Satow et al. [2021] provide a robust $400 \mathrm{kyr}$ chronology for eruptions, which range from large caldera-forming events to lavas. Focussing on 224-0 ka, for which there is a good geological record, and based on a critical sea level of $-40 \mathrm{~m}$ and time lags (see figure 4 in Satow et al. [2021]), there are two periods of inactivity at the volcano; between $\sim 205$ and $180 \mathrm{ka}$ and 120 and $85 \mathrm{ka}$. The first of these two periods nonetheless coincides with at least one Plinian eruption. These two inactive periods account for about $15-30 \%$ of the 224 kyr period. This is indicated on Fig 3, where the fraction of active time (calculated using the lag times of Satow et al. [2021]) is plotted for different values of critical sea level. A change of $10 \mathrm{~m}$ in this critical value changes the percentage of predicted activity by $\sim 10 \%$. The $-40 \mathrm{~m}$ condition coincides with the range from the geological record (i.e., volcanic activity for about $70-85 \%$ of the period). If their model is implemented in 3D (Fig. 1f), the critical sea level drop is $-105 \mathrm{~m}$, which is the active condition for less than $1 \%$ of the period. Notably, these changes in sea level are all based on lithostatic equilibrium at $0 \mathrm{~m}$ sea level, which requires that there are no major changes to crustal loading (such as repeatedly building the edifice) since $400 \mathrm{ka}$, despite sea level having been below $-40 \mathrm{~m}$ for $\sim 75 \%$ of that time.

\section{Loading conditions at the volcano are omitted}

Omission of the mantle means the 2D Satow et al. [2021] model generates stresses over large scales due to extensive and unphysical bending of the crust. Consequently, important local changes to loading conditions, including the edifice itself, have little to no effect on their model results. There are several factors that may contribute to changes in surface loading conditions in addition to sea level change [McGuire et al., 1997; Satow et al., 2021], such as direct glacial loading or unloading [Albino et al., 2010], edifice collapse [Lundgren et al., 2003] or construction [Pinel \& Jaupart, 2000], erosion [Thouret, 1999], and/or volcano hydrology [Farquharson \& Amelung, 2020]. Surface loads should be considered in the context of loading conditions at depth also, such as magma chamber recharge and deflation [Browning et al., 2015] including at multiple storage levels [Druitt et al., 2019], thermal and mechanical variations at the chamber(s) [Browning et al., 2021], the conditions for melting at source [Sigmundsson et al., 2010], and the tectonic stress state [Stephens et al., 2017]. Several of these loading conditions will have much greater influence than sea level change 
given that $110 \mathrm{~m}$ of water column is equivalent to $40-50 \mathrm{~m}$ of higher-density rock overburden; this height is small in the context of the changes expected during edifice growth and caldera formation. Minor changes to loads driven by sea level change, may only serve to trigger volcanoes that were already close to eruption [Caricchi et al., 2021]. Santorini is associated with four caldera-events, with the most recent (Minoan) potentially removing a rock volume of $\sim 17 \mathrm{~km}^{3}$ [Karatson et al., 2020]; equivalent to removing $200 \mathrm{~m}$ of sea water column over the whole island. It is difficult to envisage how this and other major volume changes directly above the magma chamber should not change the state of equilibrium at the volcano.

\section{REFERENCES}

Albino, F., Pinel, V. and Sigmundsson, F., 2010. Influence of surface load variations on eruption likelihood: application to two Icelandic subglacial volcanoes, Grímsvötn and Katla. Geophysical journal international, 181(3), pp.1510-1524.

Browning, J., Drymoni, K. and Gudmundsson, A., 2015. Forecasting magma-chamber rupture at Santorini volcano, Greece. Scientific reports, 5(1), pp.1-8.

Browning, J., Karaoğlu, Ö.Z.G.Ü.R., Bayer, Ö., Turgay, M.B. and Acocella, V., 2021. Stress fields around magma chambers influenced by elastic thermo-mechanical deformation: implications for forecasting chamber failure. Bulletin of Volcanology, 83(7), pp.1-13.

Caricchi, L., Townsend, M., Rivalta, E. and Namiki, A., 2021. The build-up and triggers of volcanic eruptions. Nature Reviews Earth \& Environment, pp.1-19.

Druitt, T.H., Mellors, R.A., Pyle, D.M. and Sparks, R.S.J., 1989. Explosive volcanism on Santorini, Greece. Geological magazine, 126(2), pp.95-126.

Druitt, T.H., Pyle, D.M. and Mather, T.A., 2019. Santorini volcano and its plumbing system. Elements: An International Magazine of Mineralogy, Geochemistry, and Petrology, 15(3), pp.177-184.

Farquharson, J.I. and Amelung, F., 2020. Extreme rainfall triggered the 2018 rift eruption at Kìlauea Volcano. Nature, 580(7804), pp.491-495.

Grant, K.M., Rohling, E.J., Ramsey, C.B., Cheng, H., Edwards, R.L., Florindo, F., Heslop, D., Marra, F., Roberts, A.P., Tamisiea, M.E. and Williams, F., 2014. Sea-level variability over five glacial cycles. Nature communications, 5(1), pp.19.

Karátson, D., Telbisz, T., Gertisser, R., Strasser, T., Nomikou, P., Druitt, T., Vereb, V., Quidelleur, X. and Kósik, S., 2020. Constraining the landscape of Late Bronze Age Santorini prior to the Minoan eruption: Insights from volcanological, geomorphological and archaeological findings. Journal of Volcanology and Geothermal Research, 401, p.106911.

Kirsch, C., 1898. Die theorie der elastizitat und die bedurfnisse der festigkeitslehre. Zeitschrift des Vereines Deutscher Ingenieure, 42, pp.797-807.

Lundgren, P., Berardino, P., Coltelli, M., Fornaro, G., Lanari, R., Puglisi, G., Sansosti, E. and Tesauro, M., 2003. Coupled magma chamber inflation and sector collapse slip observed with synthetic aperture radar interferometry on Mt. Etna volcano. Journal of Geophysical Research: Solid Earth, 108(B5).

McGuire, W.J., Howarth, R.J., Firth, C.R., Solow, A.R., Pullen, A.D., Saunders, S.J., Stewart, I.S. and Vita-Finzi, C., 1997. Correlation between rate of sea-level change and frequency of explosive volcanism in the Mediterranean. Nature, 389(6650), pp.473-476.

Pinel, V. and Jaupart, C., 2000. The effect of edifice load on magma ascent beneath a volcano. Philosophical Transactions of the Royal Society of London. Series A: Mathematical, Physical and Engineering Sciences, 358(1770), pp.1515-1532.

Satow, C., Gudmundsson, A., Gertisser, R., Ramsey, C.B., Bazargan, M., Pyle, D.M., Wulf, S., Miles, A.J. and Hardiman, M., 2021. Eruptive activity of the Santorini Volcano controlled by sea-level rise and fall. Nature Geoscience, pp.1-7.

Sigmundsson, F., Pinel, V., Lund, B., Albino, F., Pagli, C., Geirsson, H. and Sturkell, E., 2010. Climate effects on volcanism: influence on magmatic systems of loading and unloading from ice mass variations, with examples from Iceland. Philosophical Transactions of the Royal Society A: Mathematical, Physical and Engineering Sciences, 368(1919), pp.2519-2534.

Stephens, T.L., Walker, R.J., Healy, D., Bubeck, A., England, R.W. and McCaffrey, K.J., 2017. Igneous sills record far-field and near-field stress interactions during volcano construction: Isle of Mull, Scotland. Earth and Planetary Science Letters, 478, pp.159-174.

Thouret, J.C., 1999. Volcanic geomorphology-an overview. Earth-science reviews, 47(1-2), pp.95-131.

\section{FIGURES}


A: 2D Model: $-110 \mathrm{~m}$, without deformation

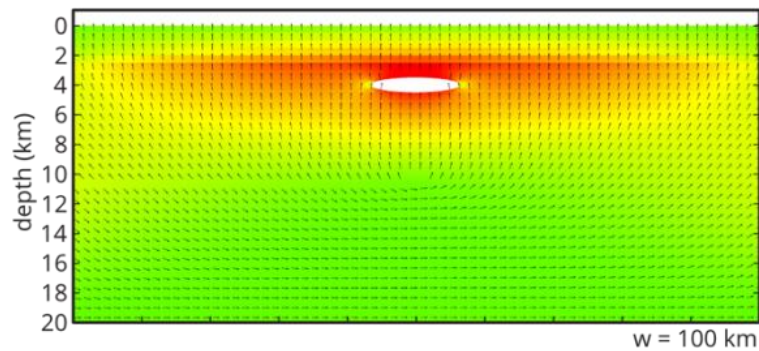

B: 2D Model: $-110 \mathrm{~m}$, full extent, with exaggerated deformation
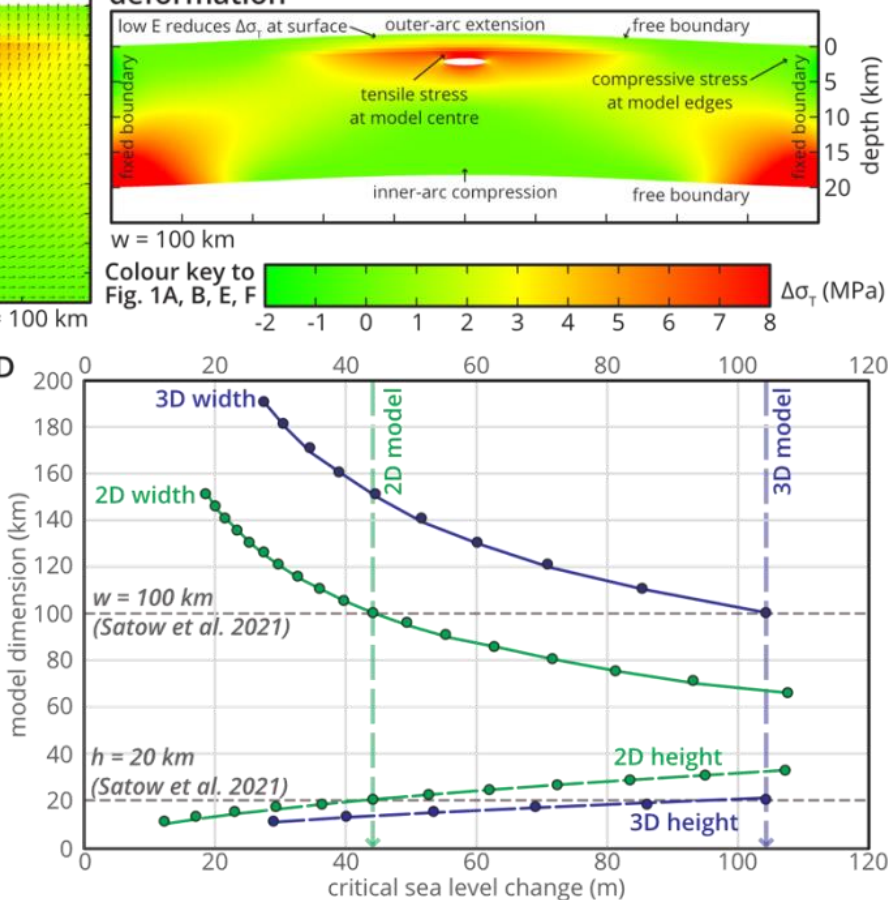

F: Axisymmetric Model: $-110 \mathrm{~m}$, with exaggerated deformation
D

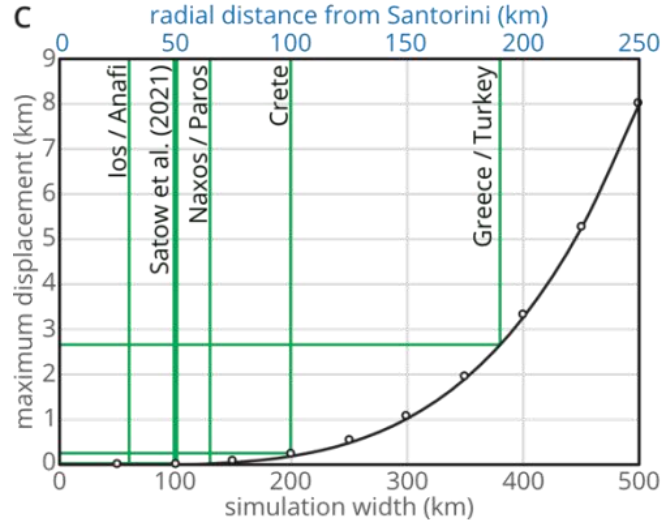

E: 2D Model: -110 m, no magma chamber with exaggerated deformation

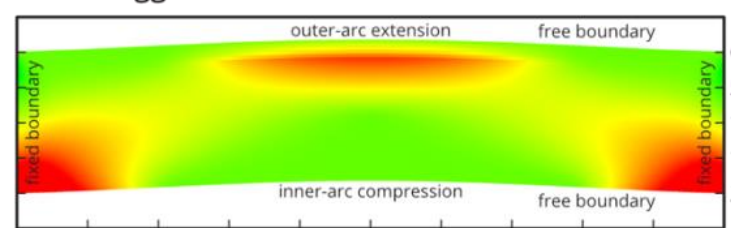

$\mathrm{w}=100 \mathrm{~km}$

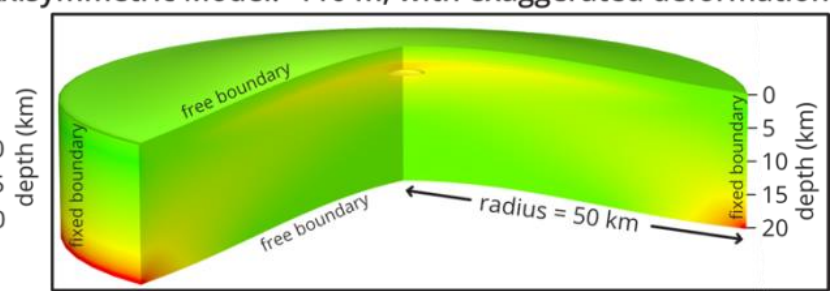

Figure 1. Elastic bending beam model based on the description of Satow et al. (2021). (A) Reproduction of the published model, showing maximum change in tensile stress at $-110 \mathrm{~m}$. Arrows show maximum compressive stress axis. cf. their figure 2. (B) Full view of the simulation result shown in (A), here with exaggerated deformation. The vertical ends are fixed and both horizontal surfaces are free. With model dimensions $w=100 \mathrm{~km}$ and $h=20 \mathrm{~km}$, the maximum tensile stress change (around the chamber) and displacement for $-110 \mathrm{~m}$ sea level change are $8.7 \mathrm{MPa}$ and 17.9 m. (C) Effect of changing $w$ on central displacement, for $h=20 \mathrm{~km}$. (D) Effect of changing the model dimensions, width with fixed height $(h=20 \mathrm{~km})$, or height with fixed width $(w=100 \mathrm{~km})$, for 2D and 3D (axisymmetric) model space. (E) The Satow et al., (2021) model, without a magma chamber. Conditions are otherwise as published. (F) Perspective view of the axisymmetric version of the model. The maximum tensile stress change and displacement are now $3.7 \mathrm{MPa}$ and $7.2 \mathrm{~m}$. Deformation in B, E, and $F$ is exaggerated by a factor of 100 .
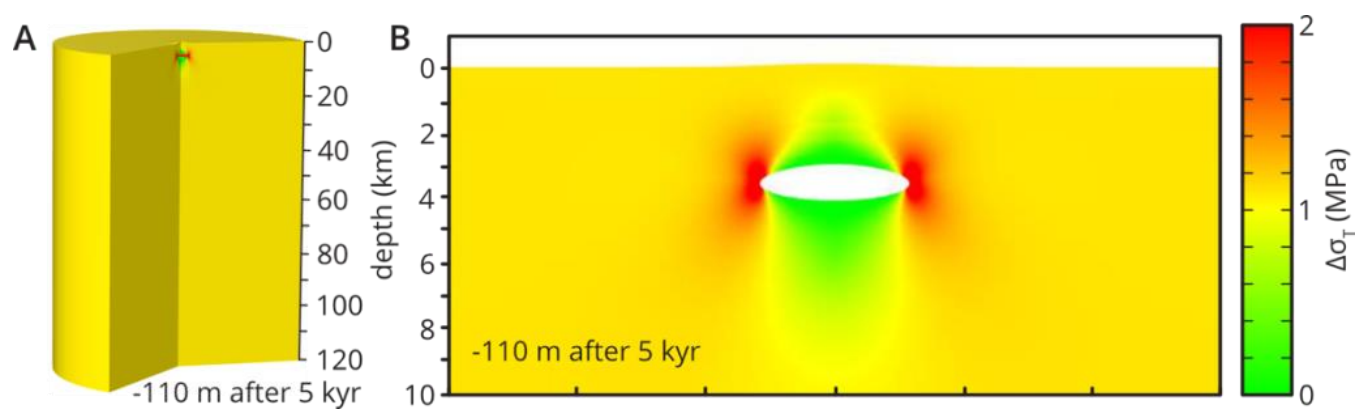

Figure 2. Maximum tensile stress change for $-110 \mathrm{~m}$ sea level change, for an axisymmetric model with viscous lower region: viscosity is $1 \times 10^{19} \mathrm{~Pa} \cdot \mathrm{s}$ and $E=130 \mathrm{GPa}$ (after [Sigmundsson et al., 2010]). The vertical edges are no longer fixed; all other conditions are as described by Satow et al. 
192 (2021). (A) The whole simulation showing universal stress change of $1.1 \mathrm{MPa}$, and local stress 193 perturbation at the chamber. (B) The maximum tensile stress change at the chamber is $11.3 \mathrm{MPa}$ 194 and the surface bulge above the magma chamber is $0.15 \mathrm{~m}$ high. The deformation is exaggerated 195 by 1000 . Note that due to time dependence introduced by the viscous mantle, this is the stable 196 stress state after 5 kyr.

197

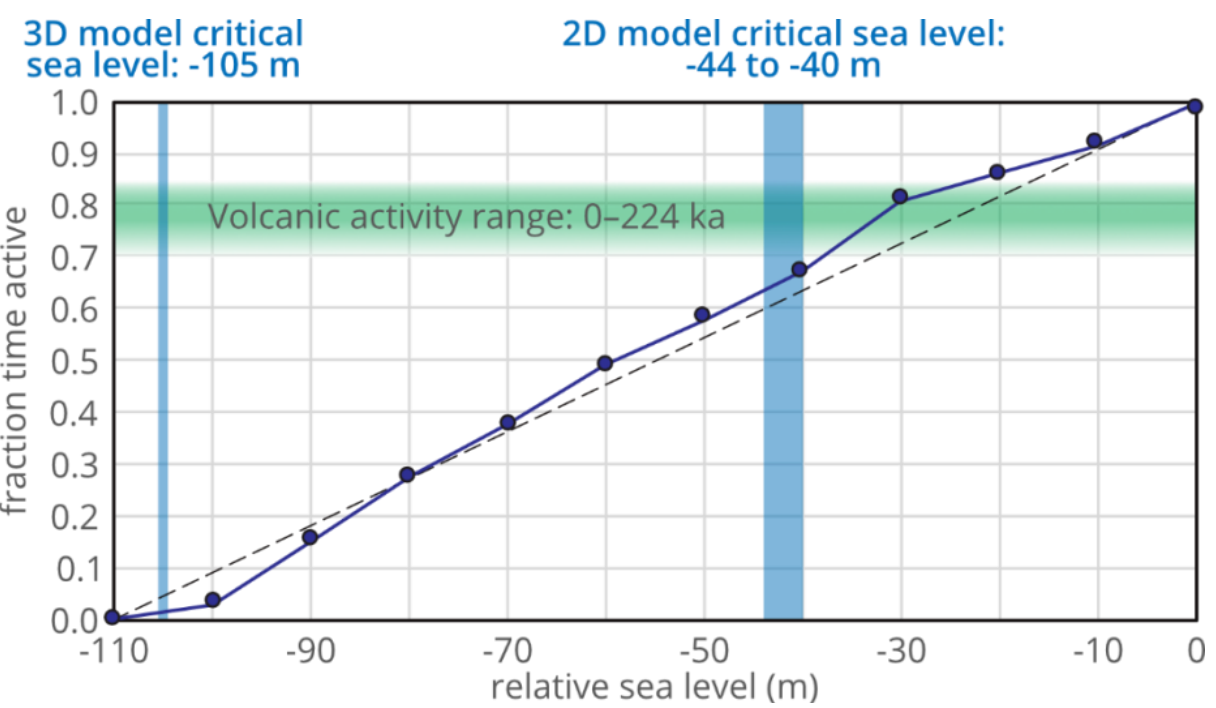

Figure. 3. Sea level fraction for the $0-224$ ka period showing the fraction of time that the volcano has been active (green zone). Blue fields highlight sea level change required for activity in the 2D and 3D versions of the Satow et al., 2021 model; i.e., the 3.5 MPa tensile stress condition. 